\title{
FoodSMART: A mobile phone application to provide personalised information on the foods available in an eating out situation.
}

\author{
KM Appleton ${ }^{1}$, J Bray ${ }^{1}$, I Mavridis², A Giboreau ${ }^{3}$, FJA Perez-Cueto 4 , M Ronge ${ }^{5}$, H Hartwell ${ }^{1}$ \\ ${ }^{1}$ Bournemouth University, Poole, UK; ${ }^{2}$ University of Macedonia, Thessalonika, Greece; \\ ${ }^{3}$ Institut Paul Bocuse, Ecully, France; ${ }^{4}$ University of Copenhagen, Copenhagen, Denmark; \\ ${ }^{5}$ Ronge \& Partners, Baden, Austria.
}

\begin{abstract}
INTRODUCTION
Eating out has become an integral part of modern living, but meals consumed out of the home are often high in calories and fat (1). Providing information on foods and dishes (e.g. on nutritional content, allergens, and food provenance) has been associated with improved dietary intakes, but concerns have also been expressed $(2,3)$. Consumers welcome increased information, but only if the information is easily accessible and relevant to them ${ }^{(2,3)}$.

This work aimed to develop a mobile phone application (app) to allow consumers to personalise the information they receive on the foods and dishes provided when eating out.
\end{abstract}

\section{METHODS}

The app was demonstrated to consumers at eight public engagement events -

Four events in the UK (79 respondents)

One event in France (54 respondents)

One event in China (48 respondents)

One event in Malaysia (34 respondents)

One event in Denmark (18 respondents).

Perceptions were assessed using the 10-item System Usability Scale (SUS) questionnaire (4), plus an additional question 'I believe the FoodSmart App will be useful to customers in a canteen setting to help them to get informed about dishes offered'.

\section{RESULTS}

233 respondents provided usable data:

$81(35 \%)$ males, $143(61 \%)$ females;

$115(49 \%)$ aged $20-29$ y, 39 (17\%) aged $30-39$ $y, 35(15 \%)$ aged $40-49$ y, $32(14 \%)$ aged $50+y$. All questions were responded to positively (smallest $\mathrm{t}(229)=26.40, \mathrm{p}<0.05)$. Mean overall SUS score $=68.3 / 100($ sd.: 15.4 , range: 27.50 males and females or over age (largest $\mathrm{t}(196)=0.81, \mathrm{p}=0.42)($ Table 1$)$. -100). No differences were found between

\section{THE FoodSMART APP}

The app is intended for use in workplace canteens, where a predetermined food menu offers a number of dishes and side-dishes per day.

Initial stages of app development gained the information that consumers would like to receive, the information they would like to be able to personalise, and how this information should best be presented (3).

An app was then developed consisting of a user interface (Figure 1) attached to a secure database. The database stores information per dish, the user interface allows consumers to input preferences about the information / dish that they receive. The app is activated by scanning a QR code on a menu, to provide information easily, and the consumer then receives the information they desire.

Figure 1: Images of the FoodSMART app


Table 1: Mean (SD) SUS scores based on demographic variables

\begin{tabular}{|l|l|l|l|l|}
\hline Demographic & & $\begin{array}{l}\text { Mean (SD) } \\
\text { SUS score }\end{array}$ & $\begin{array}{l}\text { Mean (SD) } \\
\text { SUS score }\end{array}$ \\
\hline Gender & Male & $69.8(14.6)$ & Female & $67.9(15.8)$ \\
\hline Age & $20-29$ y & $67.0(13.6)$ & $40-49$ y & $64.4(19.7)$ \\
\hline & $30-39$ y & $73.9(14.2)$ & $50+\mathrm{y}$ & $71.9(16.4)$ \\
\hline
\end{tabular}

\section{DISCUSSION}

We found positive perceptions of the app, from a range of consumers.

SUS scores were typical of those for other similar IT equipment, such as mobile phones and modems ${ }^{(5)}$. Promise, in terms of engagement and use is suggested. Impacts of the app on dietary choices will be ascertained in future work.

Funded by grant EU-H2020-RISE-634999: FoodSMART.

\section{REFERENCES}

1.Lachat C, et al. Obes Rev. 2012, 13, 329-46.

2. Brinberg D, et al. Appetite, $2000,35,35-43$.

3. Price S, et al. Food Qual Pref. 2016, 53, 39-46

4. Brooke, J. J Usability Stud. 2013, 8, 29-40.

5. Bangor A, et al. Int J Human-Computer Interaction, 2008, 24, 574-594. 